\title{
Budget Impact Analysis of Ixabepilone Used According to FDA- Approved Labeling in Treatment-Resistant Metastatic Breast Cancer
}

\author{
Joanne Ho, PhD; Lihua Zhang, MD, PhD; Lora Todorova, MPH; Finlay Whillans; \\ Patricia Corey-Lisle, PhD, RN; and Yong Yuan, PhD
}

\begin{abstract}
BACKGROUND: Breast cancer is one of the most common forms of cancer in the United States, with approximately $10 \%$ of newly diagnosed patients presenting with metastatic disease. Limited therapy options make the successful treatment of metastatic breast cancer (MBC) difficult. Current treatment options include drugs belonging to the classes of anthracyclines and taxanes as well as the drug capecitabine. Resistance to these classes of drugs is often acquired, thus highlighting the need for newer agents capable of managing treatment resistant disease. Ixabepilone is an antineoplastic agent from the epothilone class that was FDA-approved in 0ctober 2007 for the treatment of metastatic or locally advanced breast cancer. The FDA-approved indications for ixabepilone specify (a) use of ixabepilone in combination with capecitabine for the treatment of patients with metastatic or locally advanced breast cancer after (resistance to) treatment with an anthracycline and a taxane, or whose cancer is taxane resistant and for whom further anthracycline therapy is contraindicated; and (b) ixabepiIone as a monotherapy for the treatment of metastatic or locally advanced breast cancer in patients whose tumors are resistant or refractory to an anthracycline, a taxane, and capecitabine.
\end{abstract}

OBJECTIVES: To estimate the 3-year projected impact on the annual pharmacy budget for a hypothetical 1 million-member commercial plan that introduces and reimburses ixabepilone therapy for its FDA-approved indications: either as a monotherapy for patients pretreated with combined anthracyclines, taxanes, and capecitabine (ATC-p) or in combination with capecitabine for patients pretreated with anthracyclines and taxanes (AT-p).

METHODS: U.S. prevalence and treatment data for MBC patients were obtained from published and nonpublished sources. The MBC population was stratified into AT-p and ATC-p populations. These 2 groups comprised the assumed study population. The model considered 2 scenarios-without (pre) and with (post) ixabepilone, either as monotherapy for ATC-p or combination therapy with capecitabine for AT-p patients. Market share data for chemotherapeutic treatment options for MBC pre-ixabepilone and in the first year post-ixabepilone were obtained from nonpublished, proprietary, real-world drug utilization data collected by IntrinsiQ LLC (Waltham, MA), for 2007 and 2008, respectively. Market shares for the second and third years post-ixabepilone were forecasted by the study authors based on IntrinsiQ data collected from January 2008 to January 2009 and the observed switching patterns in the 2007 and 2008 IntrinsiQ data.

Drug costs were based on First DataBank Inc. Wholesale Acquisition Cost (accessed March 2009). The results for each indication were analyzed individually and summed to reflect the total impact of ixabepilone. Results were also considered on a per member per month (PMPM) basis to examine the relative impact on the plan. Sensitivity of the results to model assumptions was tested using univariate sensitivity analyses on the prevalence of AT-p and ATC- $p$, the price of ixabepilone, the price of comparator medications, and the ixabepilone market uptake. A key assumption was that ixabepilone would be used only in accordance with its current labeled indications.

RESULTS: In a health plan population of 1 million members, the estimated number of female patients aged 20 years or older with recurrent MBC and previous treatment with either AT or ATC was 15 over the 3-year time horizon used in this budget impact model. For AT-p patients, the estimated incremental cost PMPM was $\$ 0.002$ for each of the 3 years. The estimated incremental cost PMPM for the ATC-p population was $\$ 0.003$ for year 1 and $\$ 0.004$ for both year 2 and year 3 . In sensitivity analyses, the PMPM impact varied between $-\$ 0.01$ and $\$ 0.02$ over the 3-year period. The model was most sensitive to the cost of ixabepilone.

CONCLUSION: Given the poor prognosis and limited number of treatment options for patients with MBC, the need for widespread coverage of ixabepilone in accordance with FDA-approved indications can clearly be established. Assuming that ixabepilone is used only for its currently labeled indications, both the number of patients eligible for ixabepilone treatment and the expected budget impact of covering ixabepilone for this group of patients are relatively small.

J Manag Care Pharm. 2009;15(6):467-75

Copyright $\odot 2009$, Academy of Managed Care Pharmacy. All rights reserved.

\section{What is already known about this subject}

- In the United States, breast cancer is the second most common form of cancer and the second leading cause of cancer deaths among women. More than 1 out of 3 women with breast cancer initially present with or later develop metastatic disease. Metastatic breast cancer (MBC) is considered terminal, with a median survival of approximately 2 years.

- Before the 2007 approval of ixabepilone by the FDA, capecitabine was the only approved drug for treating MBC in patients who failed treatment with anthracycline and taxanes (AT), and there were no FDA-approved treatment options for patients who were no longer responding to anthracycline, taxane, and capecitabine (ATC) therapy.

- Ixabepilone has demonstrated activity in metastatic and locally advanced breast cancer, both as a monotherapy and when combined with capecitabine. In the pivotal phase III clinical trial, adding ixabepilone to capecitabine prolonged progression-free survival (median 5.8 months vs. 4.2 months for capecitabine alone, HR for progression $=0.75,95 \% \mathrm{CI}=0.64-0.88, P<0.001$ ).

\section{What this study adds}

- This budget impact analysis is the first to estimate the pharmacy budget impact to a health plan after introducing ixabepilone as a treatment option for MBC patients who have previously failed AT-based regimens.

- The model estimated that adding ixabepilone to a health plan's formulary for use in accordance with its labeled indications has minimal impact on the pharmacy budget. At an annual per patient pharmacy cost of $\$ 28,008$ for patients previously treated with AT and $\$ 20,898$ for patients previously treated with ATC, the increase in per member per month (PMPM) cost would be less than $\$ 0.01$ during the first 3 years. 
I the United States, breast cancer is the second most common form of cancer and the second-leading cause of cancer deaths among women. In 2009, an estimated 192,370 American women will be diagnosed with this disease. ${ }^{1}$ While the majority of women will be diagnosed during earlier stages of the disease when curative approaches are possible, approximately $10 \%$ of newly diagnosed patients have locally advanced or metastatic disease. ${ }^{2}$ Once metastases are detected, the median survival time is approximately 18-24 months. ${ }^{3}$ Recent estimates show that the 5-year survival rate for women with metastatic breast cancer (MBC) is 27\%. ${ }^{1}$ In 2006, it was estimated that close to 50,000 women across North America died from MBC, and that more than 400,000 women worldwide will die annually of this disease. ${ }^{4}$ During the advanced stages of MBC, treatments are often palliative in nature rather than curative. ${ }^{5}$

The current standard of care for systemic breast cancer treatment involves therapy with anthracyclines and/or taxanes. While response rates of $30 \%$ or more are routinely achieved in previously untreated patients, response rates decrease significantly in patients previously exposed to chemotherapy. ${ }^{6}$ With the increased use of anthracyclines and taxanes, clinicians now face the challenge of managing disease progression, or recurrence, in patients who are anthracycline and taxane resistant. ${ }^{7}$ Patients with MBC who have progressed after treatment with anthracyclines and taxanes have limited treatment choices, and many of these options have low response rates. ${ }^{8}$ In these patients, capecitabine treatment has been shown to achieve response rates ranging from $9 \%$ to $14 \%$ in phase III studies, ${ }^{9,10}$ while other agents have been shown to have less efficacy. These relatively poor response rates highlight the need for newer agents that can be used to treat individuals whose disease has progressed after treatment with anthracyclines and/or taxanes has failed.

Epothilones are a new class of nontaxane, tubulin stabilizing agents possessing potent cytotoxic activity and reduced susceptibility to a variety of multidrug resistance mechanisms that lead to taxane resistance. ${ }^{11}$ Ixabepilone (BMS-247550) is a semisynthetic analog of the natural product epothilone $B$. It was designed to have improved pharmacological properties, while retaining the activity and resistance profile of the natural compound. ${ }^{12}$ Ixabepilone has demonstrated activity in metastatic and locally advanced breast cancer, both as a monotherapy ${ }^{13}$ and when combined with capecitabine. ${ }^{14}$ In the pivotal phase III clinical trial, adding ixabepilone to capecitabine prolonged progression-free survival (median 5.8 months vs. 4.2 months for capecitabine alone, HR for progression $=0.75,95 \% \mathrm{CI}=0.64-0.88, P<0.001) .{ }^{15}$ Although results from clinical trials are able to demonstrate the clinical efficacy of ixabepilone, in health care environments with limited financial resources, new therapies such as ixabepilone are also closely scrutinized for the potential impact they may have upon pharmacy budgets.
The objective of this study was to model the annual direct pharmacy cost of introducing ixabepilone as a treatment option for patients with MBC. Specifically, we considered the impact upon a hypothetical health plan with 1 million members over a 3-year time horizon, where ixabepilone therapy was used as a monotherapy for patients previously treated with the combination of anthracyclines, taxanes, and capecitabine or ixabepilone in combination with capecitabine for patients previously treated with anthracyclines and taxanes. Only ixabepilone use strictly in accordance with its currently labeled indications was considered.

\section{Methods}

\section{Model Structure and Calculations}

The model analysis was conducted according to the budget impact analysis guidelines promulgated in 2007 by the International Society for Pharmacoeconomics and Outcomes Research (ISPOR). ${ }^{16}$ The target study population for ixabepilone treatment is female $\mathrm{MBC}$ patients who are aged 20 years or older and are anthracycline and taxane pretreated (AT-p) or anthracycline, taxane, and capecitabine pretreated (ATC-p). For the hypothetical plan membership, the population percentages and respective patient numbers considered in the analysis are shown in Table 1. Breast cancer prevalence data were drawn from the Surveillance, Epidemiology, and End Results (SEER) Cancer Statistics Review 1975-2005 for U.S. prevalence counts (invasive cancers only), January 2005 , by age at prevalence. ${ }^{17}$ Specifically, the number of females aged 20 years or older with breast cancer was used to calculate the prevalence, assuming the U.S. population to be approximately 300,000,000 individuals. The proportion of female breast cancer patients with MBC was derived from U.S. SEER data using CancerMPact Comprehensive Cancer Epidemiology data purchased from The MattsonJack Group, Inc. (St. Louis, MO). ${ }^{18}$ The AT-p and ATC-p prevalence rates were taken from 2007 market research data purchased from IntrinsiQ (IntrinsiQ LLC Waltham, MA). ${ }^{19}$ IntrinsiQ data are derived from the electronic collection of patient-level drug utilization data from 36 states, which are updated on a monthly basis. ${ }^{19}$

The populations identified to receive therapy were modeled according to market share distributions in the pre-ixabepilone scenario (market without ixabepilone) and the post-ixabepilone market (with ixabepilone). In the pre-ixabepilone scenario, it was assumed that ixabepilone is not available for use in the patient population, whereas the post-ixabepilone scenario assumed that ixabepilone was listed on the formulary as a treatment option for treatment-resistant MBC only. For each of the 3 years modeled in the analysis, a cross-sectional assessment of a payer budget was taken, where the pre-ixabepilone market was assumed to be constant. Both the pre- and first-year post-ixabepilone scenarios were derived from proprietary nonpublished data that were purchased from IntrinsiQ by the study authors for use in this model. Real-world drug utilization data for 2007 were used for the pre-ixabepilone scenario, while 2008 utilization data were 


\section{TABLE 1 Model Population Parameters for Budget Impact Analysis ${ }^{a}$}

\begin{tabular}{|c|c|c|}
\hline Model Population Parameters & $\%$ & Number of Patients \\
\hline Hypothetical plan membership & & $1,000,000$ \\
\hline \multicolumn{3}{|l|}{ Prevalence of Breast Cancer } \\
\hline Female patients with breast cancer (aged 20 years or older) ${ }^{b}$ & $0.8 \%$ & 8,259 \\
\hline Female patients with $\mathrm{MBC}^{\mathrm{c}}$ & $6.9 \%$ & 570 \\
\hline Female patients with MBC who are AT-p ${ }^{d}$ & $17.0 \%$ & 97 \\
\hline Female patients with MBC who are ATC-p ${ }^{d}$ & $26.0 \%$ & 148 \\
\hline Female patients with MBC receiving other treatments (not AT-p or ATC-p)d & $57.0 \%$ & 325 \\
\hline \multicolumn{3}{|c|}{ a Numbers shown in the table may not exactly multiply or sum to totals shown because of rounding. } \\
\hline \multicolumn{3}{|c|}{$\begin{array}{l}{ }^{b} \text { From SEER Cancer Statistics Review 1975-2005, Table 1-22.17 Prevalence was calculated as the total number of U.S. females aged } 20 \text { years or older with breast cancer } \\
(N=2,477,777) \text { divided by an estimated U.S. population of 300,000,000 individuals. }\end{array}$} \\
\hline \multicolumn{3}{|c|}{$\begin{array}{l}\text { 'From The MattsonJack Group, Inc. } 2008 \text { CancerMPact Comprehensive Cancer Epidemiology data. }{ }^{18} \\
\text { dFrom IntrinsiQ } 2007 \text { market research data. }{ }^{19}\end{array}$} \\
\hline \multicolumn{3}{|c|}{$\begin{array}{l}\text { dFrom IntrinsiQ } 2007 \text { market research data. }{ }^{19} \\
\text { ATC-p = pretreated with anthracyclines, taxanes, and capecitabine; AT-p=pretreated with anthracyclines and taxanes; MBC=metastatic breast cancer; }\end{array}$} \\
\hline \multicolumn{3}{|c|}{$\begin{array}{l}\text { ATC- } p=\text { pretreated with anthracyclines, taxanes, and capecitabine; AT-p = pretreated with anthracyclines and taxanes; MBC = metastatic breast cancer; } \\
\text { SEER = Surveillance, Epidemiology, and End Results. }\end{array}$} \\
\hline
\end{tabular}

used for the first year post-ixabepilone (year 1). Both data sets were collected by IntrinsiQ. ${ }^{19}$

Market shares for the second and third years post-ixabepilone (year 2, year 3) were then forecasted by the study authors using the drug utilization data collected by IntrinsiQ from January 2008 to January 2009, combined with the market uptakes and switching patterns observed in the 2007 to 2008 IntrinsiQ drug utilization data. Because ISPOR guidelines do not recommend a method for forecasting the budget impact of off-label use, ${ }^{16}$ it was assumed that use of ixabepilone would be limited to its currently labeled indications only.

To project the ixabepilone market uptake trends for year 2 and year 3, a trend analysis was conducted using the 13-month (January 2008 through January 2009) IntrinsiQ market research data as the basis for the analysis. To confirm the results of the forecasting analysis, a 3-month moving average approach was applied starting with the first 3 months of January 2008 and forecasting through January 2009 to project market share values for year 2 and year 3. Similar results were obtained using both methods. The remaining market share not receiving ixabepilone therapy was then allocated proportionally based on the preixabepilone distribution.

To establish the annual pharmacy costs for each treatment, the average annual costs were calculated based on the average course of treatment. Drug costs were based on wholesale acquisition cost (FirstDataBank Inc., San Bruno, CA; accessed March 2009). ${ }^{20}$ The annual pharmacy costs were calculated using the recommended dosing schedules, based on the respective product information sheets. ${ }^{21-35}$ The median cycle lengths of all drug therapies were based on opinions provided by physicians employed or retained by the study sponsor. Details of these calculations are available upon request. Rebates and copayments were not included in the analysis. The projected pharmacy costs for each treatment were then applied to the pre- and post-ixabepilone market shares to calculate the estimated incremental budget impact of adding ixabepilone to the hypothetical formulary for years 1,2 , and 3 for the AT-p and ATC-p markets, respectively. All therapies considered within the model were assumed to have similar clinical efficacy and side effect profiles.

The results for each indication, AT-p and ATC-p, were summed to estimate the incremental budget impact for all patients with treatment-resistant MBC. Since the formula is arbitrarily chosen to represent 1 million members, the results are presented in a standardized format of incremental impact per member per month (PMPM).

Model assumptions were tested using multiple univariate sensitivity analyses. The prevalence of AT-p and ATC-p, the price of ixabepilone, the price of comparator medications, and ixabepilone market uptake were all varied by $+/-50 \%$ from the base case. A larger $+/-50 \%$ range was chosen, in contrast to the more typical ranges of $+/-20 \%$ or $25 \%$, in order to better account for any reasonable variations of the assumptions used in the model. An increased mortality rate of 5\% for each year and rates of $80 \%$ or $90 \%$ drug compliance for ixabepilone were also included in the sensitivity analyses. Two separate 4-way sensitivity analyses were also conducted to assess best-case and worst-case scenarios for ixabepilone. For the best-case analysis, a 50\% decrease in the prevalence rate, a $50 \%$ decrease in the ixabepilone market uptake rate, a 50\% increase in the cost of other drugs, and a 50\% decrease in the ixabepilone price were assumed. For the worst-case analysis, a $50 \%$ increase in the prevalence rate, a $50 \%$ increase in the market uptake, a $50 \%$ decrease in the cost of other drugs, and a $50 \%$ increase in the ixabepilone price were assumed.

An Excel spreadsheet-based model using Visual Basic for Applications (Microsoft Corporation, Redmond, WA) was created for all modeling calculations and simulations. The resulting estimates were reported in 2009 U.S. dollars for years 1, 2, and 3. 


\section{TABLE 2 Market Share Scenario Inputs for AT-p Population for Years 1 Through $3^{a}$}

\begin{tabular}{|c|c|c|c|c|c|c|c|c|c|c|c|c|c|c|c|}
\hline & \multirow[b]{3}{*}{$\#$} & \multirow{2}{*}{\multicolumn{2}{|c|}{ Pre-IXA }} & \multicolumn{4}{|c|}{ Year 1} & \multicolumn{4}{|c|}{ Year 2} & \multicolumn{4}{|c|}{ Year 3} \\
\hline & & & & \multicolumn{2}{|c|}{ Switching } & \multicolumn{2}{|c|}{$\begin{array}{c}\text { Post-IXA } \\
\text { Distribution } \\
\end{array}$} & \multicolumn{2}{|c|}{ Switching } & \multicolumn{2}{|c|}{$\begin{array}{c}\text { Post-IXA } \\
\text { Distribution }\end{array}$} & \multicolumn{2}{|c|}{ Switching } & \multicolumn{2}{|c|}{$\begin{array}{c}\text { Post-IXA } \\
\text { Distribution }\end{array}$} \\
\hline & & $\begin{array}{c}\% \\
\text { Patients } \\
\end{array}$ & $\begin{array}{c}\# \\
\text { Patients } \\
\end{array}$ & $\begin{array}{l}\% \text { to } \\
\text { IXA }^{c}\end{array}$ & $\begin{array}{c}\# \\
\text { Patients } \\
\text { to IXA } \\
\end{array}$ & $\begin{array}{c}\% \\
\text { Patients }\end{array}$ & $\begin{array}{c}\# \\
\text { Patients }\end{array}$ & $\begin{array}{l}\% \text { to } \\
\text { IXAd }^{\text {d }} \\
\end{array}$ & \begin{tabular}{|c}
$\#$ \\
Patients \\
to IXA \\
\end{tabular} & $\begin{array}{c}\% \\
\text { Patients }\end{array}$ & $\begin{array}{c}\# \\
\text { Patients }\end{array}$ & $\begin{array}{l}\% \text { to } \\
\text { IXA }^{\text {d }}\end{array}$ & $\begin{array}{c}\# \\
\text { Patients } \\
\text { to IXA }\end{array}$ & $\begin{array}{c}\% \\
\text { Patients }\end{array}$ & $\begin{array}{c}\# \\
\text { Patients }\end{array}$ \\
\hline Column Number (C) & 1 & 2 & 3 & 4 & 5 & 6 & 7 & 8 & 9 & 10 & 11 & 12 & 13 & 14 & 15 \\
\hline Calculation & & & $\mathrm{C} 2 \times 97$ & & $\mathrm{C} 4 \mathrm{x} 97$ & $\mathrm{C} 2-\mathrm{C} 4$ & $\mathrm{C} 6 \mathrm{x} 97$ & & $\mathrm{C} 8 \mathrm{x} 97$ & $\mathrm{C} 2-\mathrm{C} 8$ & $\mathrm{C} 10 \times 97$ & & $\mathrm{C} 12 \times 97$ & $\mathrm{C} 2-\mathrm{C} 12$ & $\mathrm{C} 14 \times 97$ \\
\hline Female AT-p MBC patients & 97 & & & & & & & & & & & & & & \\
\hline Bevacizumab & & 1.00 & 0.97 & 0.01 & 0.01 & 0.99 & 0.96 & 0.01 & 0.01 & 0.99 & 0.96 & 0.01 & 0.01 & 0.99 & 0.96 \\
\hline Capecitabine & & 13.00 & 12.59 & 0.36 & 0.35 & 12.64 & 12.24 & 0.36 & 0.35 & 12.64 & 12.24 & 0.35 & 0.34 & 12.65 & 12.25 \\
\hline Carboplatin & & 7.00 & 6.78 & 0.08 & 0.07 & 6.92 & 6.71 & 0.07 & 0.07 & 6.93 & 6.71 & 0.07 & 0.07 & 6.93 & 6.71 \\
\hline Cyclophosphamide & & 4.00 & 3.87 & 0.04 & 0.04 & 3.96 & 3.83 & 0.04 & 0.04 & 3.96 & 3.84 & 0.04 & 0.04 & 3.96 & 3.84 \\
\hline Docetaxel & & 10.00 & 9.69 & 0.11 & 0.11 & 9.89 & 9.58 & 0.10 & 0.10 & 9.90 & 9.59 & 0.10 & 0.10 & 9.90 & 9.59 \\
\hline Doxorubicin & & 3.00 & 2.91 & 0.03 & 0.03 & 2.97 & 2.87 & 0.03 & 0.03 & 2.97 & 2.88 & 0.03 & 0.03 & 2.97 & 2.88 \\
\hline Fluorouracil & & 2.00 & 1.94 & 0.02 & 0.02 & 1.98 & 1.92 & 0.02 & 0.02 & 1.98 & 1.92 & 0.02 & 0.02 & 1.98 & 1.92 \\
\hline Gemcitabine & & 13.00 & 12.59 & 0.66 & 0.64 & 12.34 & 11.95 & 0.67 & 0.65 & 12.33 & 11.94 & 0.65 & 0.63 & 12.35 & 11.96 \\
\hline Irinotecan & & 2.00 & 1.94 & 0.02 & 0.02 & 1.98 & 1.92 & 0.02 & 0.02 & 1.98 & 1.92 & 0.02 & 0.02 & 1.98 & 1.92 \\
\hline Methotrexate & & 2.00 & 1.94 & 0.02 & 0.02 & 1.98 & 1.92 & 0.02 & 0.02 & 1.98 & 1.92 & 0.02 & 0.02 & 1.98 & 1.92 \\
\hline Paclitaxel & & 10.00 & 9.69 & 0.11 & 0.11 & 9.89 & 9.58 & 0.10 & 0.10 & 9.90 & 9.59 & 0.10 & 0.10 & 9.90 & 9.59 \\
\hline Paclitaxel, albumin bound & & 10.00 & 9.69 & 0.11 & 0.11 & 9.89 & 9.58 & 0.10 & 0.10 & 9.90 & 9.59 & 0.10 & 0.10 & 9.90 & 9.59 \\
\hline Trastuzumab & & 2.00 & 1.94 & 0.02 & 0.02 & 1.98 & 1.92 & 0.02 & 0.02 & 1.98 & 1.92 & 0.02 & 0.02 & 1.98 & 1.92 \\
\hline Vinorelbine & & 15.00 & 14.53 & 0.42 & 0.41 & 14.58 & 14.12 & 0.41 & 0.40 & 14.59 & 14.13 & 0.41 & 0.39 & 14.59 & 14.14 \\
\hline Othere & & 6.00 & 5.81 & 0.06 & 0.06 & 5.94 & 5.75 & 0.06 & 0.06 & 5.94 & 5.75 & 0.06 & 0.06 & 5.94 & 5.75 \\
\hline Ixabepilone+capecitabine & & $\mathrm{n} / \mathrm{a}$ & $\mathrm{n} / \mathrm{a}$ & $\mathrm{n} / \mathrm{a}$ & $\mathrm{n} / \mathrm{a}$ & 2.09 & 2.02 & $\mathrm{n} / \mathrm{a}$ & $\mathrm{n} / \mathrm{a}$ & 2.03 & 1.97 & $\mathrm{n} / \mathrm{a}$ & $\mathrm{n} / \mathrm{a}$ & 2.00 & 1.93 \\
\hline Totals & 97 & 100.00 & 96.85 & 2.09 & 2.02 & 100.00 & 96.85 & 2.03 & 1.97 & 100.00 & 96.85 & 2.00 & 1.93 & 100.00 & 96.85 \\
\hline
\end{tabular}

a Numbers shown in the table may not exactly multiply or sum to totals shown because of rounding.

${ }^{b}$ Market share analysis performed by study authors using proprietary nonpublished data from IntrinsiQ LLC (Waltham, MA) for 2007.

'Market share analysis performed by study authors using proprietary nonpublished data from IntrinsiQ LLC (Waltham, MA) for 2008.

${ }^{d}$ Market share analysis performed by study authors using proprietary nonpublished data from IntrinsiQ LLC (Waltham, MA) for January 2008 to January 2009 as a basis for forecasting.

'Other=tamoxifen, anastrozole, goserelin.

$A T-p=$ pretreated with anthracyclines and taxanes; $I X A=$ ixabepilone; $M B C=$ metastatic breast cancer .

\section{Results}

Tables 2 and 3 show the market share and corresponding population distributions for both the pre-ixabepilone scenario and post-ixabepilone scenarios for years 1-3 for the AT-p and ATC-p populations, respectively. The total annual drug costs for the pre-ixabepilone scenario, the post-ixabepilone scenarios, and the incremental budget impact for years 1 through 3 are shown in Tables 4 and 5 for the AT-p and ATC-p treated populations, respectively.

Based upon IntrinsiQ market research data for ixabepilone, January 2008 to January 2009, 2.09\% of all AT-p MBC patients were assigned to receive ixabepilone in combination with capecitabine following market introduction in year 1 (Table 2). Based upon market projections from this data, it was determined that $2.03 \%$ and $2.00 \%$ would receive ixabepilone combination therapy for years 2 and 3, respectively. Based on these assumptions, it was estimated that 2 AT-p patients would be eligible for ixabepilone therapy for each of the 3 years. The estimated incremental budget impact amounts for AT-p patients were calculated to be $\$ 23,103, \$ 22,287$, and $\$ 21,943$ for years 1,2 , and 3, respectively (Table 4). When the estimated total budget was shared across all plan members, the incremental cost PMPM was $\$ 0.002$ for each of the 3 years.

For the ATC-p population, an estimated 148 patients were eligible for ixabepilone therapy, of whom 12 patients in year 1 $(8.39 \%)$ and 13 patients in each of years 2 and 3 (8.64\% and $8.61 \%$, respectively) were projected to receive ixabepilone therapy (Table 3). Based on these drug cost estimates for an ATC-p population receiving ixabepilone, the incremental budget impact amounts were $\$ 41,428$ in year $1, \$ 47,236$ in year 2 , and $\$ 47,695$ in year 3 (Table 5). When these costs were shared across the membership, the costs PMPM were $\$ 0.003$ for year 1 and $\$ 0.004$ for years 2 and 3 (Table 5).

The overall total budget impact amounts of introducing ixabepilone, aggregated for both the AT-p and ATC-p patient 


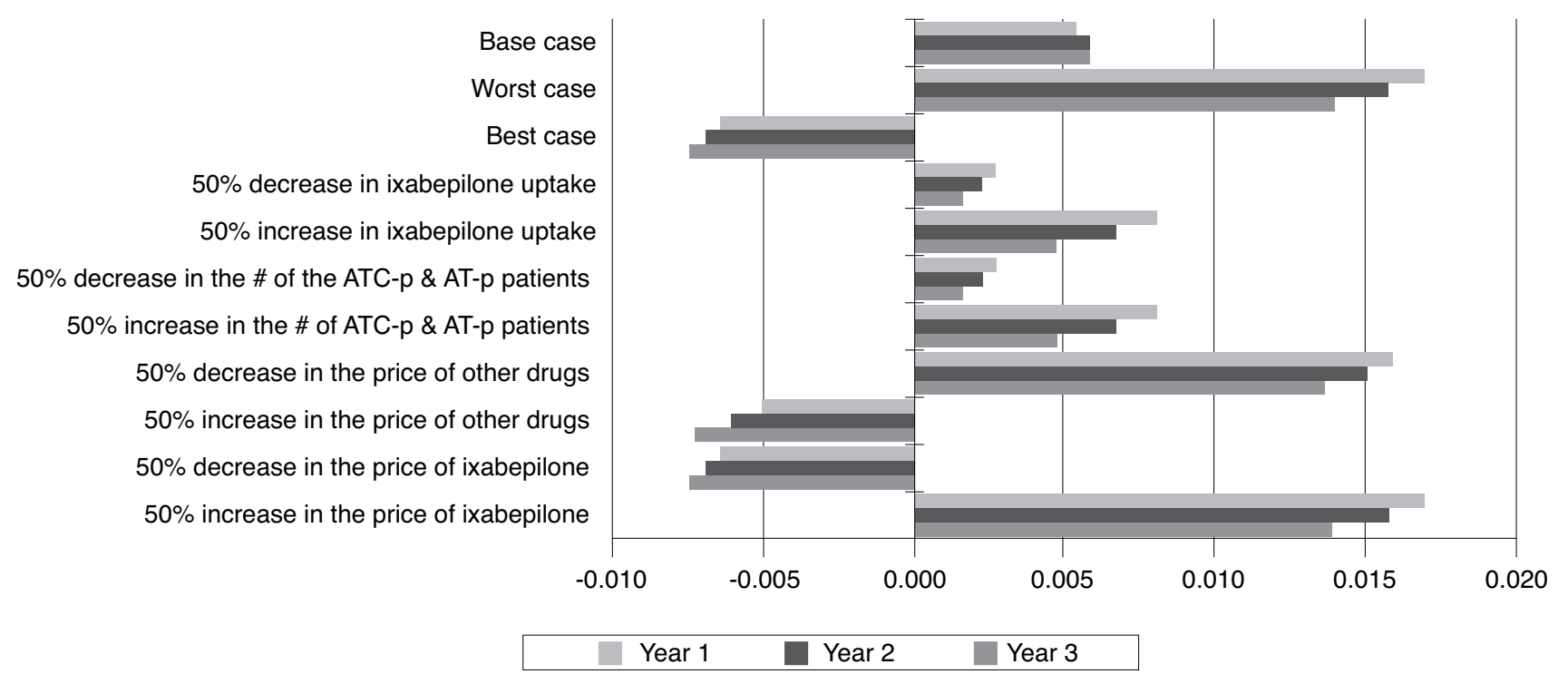

AT- $p=$ pretreated with anthracyclines and taxanes; ATC- $p=$ pretreated with anthracyclines, taxanes, and capecitabine; PMPM= per member per month.

populations, were estimated at $\$ 64,531, \$ 69,523$, and $\$ 69,638$ for years 1, 2, and 3, respectively. The aggregated AT-p and ATC-p population PMPM costs were determined to be $\$ 0.005$ for year 1 and $\$ 0.006$ for years 2 and 3 .

\section{Sensitivity Analyses}

The results of multiple 1-way sensitivity analyses to test the uncertainty surrounding model inputs showed that the incremental PMPM costs ranged from $-\$ 0.01$ to $\$ 0.02$ for each of the 3 years. Increasing the mortality rate to $5 \%$ for each year of the model time horizon or assuming $80 \%$ or $90 \%$ drug compliance for ixabepilone also had little impact upon the incremental PMPM cost. The sensitivity analysis also showed that the model was most sensitive to the cost of ixabepilone and the cost of the other MBC treatment options (Figure 1). The results of the bestcase and worst-case sensitivity analyses demonstrated that PMPM costs would vary between $\$-0.01$ and $\$ 0.02$. Overall, all scenarios tested produced little change to the PMPM costs.

\section{Discussion}

The prognosis for MBC is generally poor. Currently, patients with MBC have few viable efficacious treatment options after resistance to anthracycline, taxane, and/or capecitabine. The treatment options that are available to these patients are often viewed as primarily palliative rather than curative. Moreover, the significant amount of off-label drug use that occurs when treating these patients suggests a strong unmet medical need for new $\mathrm{MBC}$ therapies. Ixabepilone offers a new and effective treatment option for some patients. A budget impact model was developed to estimate the impact of introducing ixabepilone monotherapy or ixabepilone and capecitabine combination therapy as a treatment option for female MBC patients previously treated with other therapies in a commercial plan with a 1 million-member population.

In this model, it was estimated that the budgetary impact of adding ixabepilone to a health plan strictly in accordance with its FDA-labeled indications would be minimal. This minimal pharmacy budget impact is mostly likely attributable to the fact that the estimated size of the population to receive ixabepilone therapy, a total of 15 patients out of a hypothetical plan membership of 1 million enrollees, is relatively small. The sensitivity analysis tested various assumptions, including the estimated size of the population that would receive ixabepilone in accordance with its labeled indications and found drug price to be one of the primary driving factors for the budget impact variance.

The PMPM cost estimated in this model is relatively minor and is less than the PMPM costs of other chemotherapy agents found in the literature. For example, in an analysis of administrative pharmacy claims for an insured health plan of approximately 500,000 members, 2 newly approved medications at the time of the analyses, lenalidomide and sunitinib, were found to have PMPM costs of $\$ 0.03$ and $\$ 0.05$, respectively. Two of the most costly medications in the analysis were erlotinib and imatinib mesylate, with PMPM costs of $\$ 0.09$ and $\$ 0.12 .{ }^{36}$ In contrast, the highest PMPM cost estimated for ixabepilone in the present model for any year was $\$ 0.006$ for years 2 and 3 for 
TABLE 3 Market Share Scenario Inputs for ATC-p Population for Years 1 Through $3^{\text {a }}$

\begin{tabular}{|c|c|c|c|c|c|c|c|c|c|c|c|c|c|c|c|}
\hline & \multirow[b]{3}{*}{$\#$} & \multirow{2}{*}{\multicolumn{2}{|c|}{ Pre-IXA }} & \multicolumn{4}{|c|}{ Year 1} & \multicolumn{4}{|c|}{ Year 2} & \multicolumn{4}{|c|}{ Year 3} \\
\hline & & & & \multicolumn{2}{|c|}{ Switching } & \multicolumn{2}{|c|}{$\begin{array}{c}\text { Post-IXA } \\
\text { Distribution }\end{array}$} & \multicolumn{2}{|c|}{ Switching } & \multicolumn{2}{|c|}{$\begin{array}{c}\text { Post-IXA } \\
\text { Distribution }\end{array}$} & \multicolumn{2}{|c|}{ Switching } & \multicolumn{2}{|c|}{$\begin{array}{c}\text { Post-IXA } \\
\text { Distribution }\end{array}$} \\
\hline & & $\begin{array}{c}\% \\
\text { Patients } \\
\end{array}$ & $\begin{array}{c}\# \\
\text { Patients } \\
\end{array}$ & $\begin{array}{l}\% \text { to } \\
\text { IXAc }^{c}\end{array}$ & $\begin{array}{c}\# \\
\text { Patients } \\
\text { to IXA }\end{array}$ & $\begin{array}{c}\% \\
\text { Patients }\end{array}$ & $\begin{array}{c}\# \\
\text { Patients } \\
\end{array}$ & $\begin{array}{l}\% \text { to } \\
\text { IXA }^{\mathrm{d}}\end{array}$ & $\begin{array}{c}\# \\
\text { Patients } \\
\text { to IXA }\end{array}$ & $\begin{array}{c}\% \\
\text { Patients } \\
\end{array}$ & $\begin{array}{c}\# \\
\text { Patients } \\
\end{array}$ & $\begin{array}{l}\% \text { to } \\
\text { IXA }^{\text {d }} \\
\end{array}$ & $\begin{array}{c}\# \\
\text { Patients } \\
\text { to IXA }\end{array}$ & $\begin{array}{c}\% \\
\text { Patients } \\
\end{array}$ & $\begin{array}{c}\# \\
\text { Patients } \\
\end{array}$ \\
\hline $\begin{array}{l}\text { Column Number } \\
\text { (C) }\end{array}$ & 1 & 2 & 3 & 4 & 5 & 6 & 7 & 8 & 9 & 10 & 11 & 12 & 13 & 14 & 15 \\
\hline Calculation & & & C2x148 & & C4 4148 & $\mathrm{C} 2-\mathrm{C} 4$ & C6x148 & & C8 $\times 148$ & $\mathrm{C} 2-\mathrm{C} 8$ & C10x148 & & $\mathrm{C} 12 \times 148$ & $\mathrm{C} 2-\mathrm{C} 12$ & $\mathrm{C} 14 \times 148$ \\
\hline $\begin{array}{l}\text { Female ATC-p } \\
\text { MBC patients }\end{array}$ & 148 & & & & & & & & & & & & & & \\
\hline Capecitabine & & 20.00 & 29.63 & 1.34 & 1.98 & 18.66 & 27.64 & 0.80 & 1.19 & 19.20 & 28.44 & 0.87 & 1.29 & 19.13 & 28.34 \\
\hline Carboplatin & & 5.00 & 7.41 & 0.26 & 0.38 & 4.74 & 7.02 & 0.39 & 0.57 & 4.61 & 6.83 & 0.39 & 0.57 & 4.61 & 6.84 \\
\hline Cyclophosphamide & & 3.00 & 4.44 & 0.15 & 0.23 & 2.85 & 4.21 & 0.23 & 0.34 & 2.77 & 4.10 & 0.23 & 0.34 & 2.77 & 4.10 \\
\hline Docetaxel & & 11.00 & 16.29 & 0.57 & 0.84 & 10.43 & 15.45 & 0.85 & 1.26 & 10.16 & 15.03 & 0.85 & 1.25 & 10.15 & 15.04 \\
\hline Doxorubicin & & 2.00 & 2.96 & 0.10 & 0.15 & 1.90 & 2.81 & 0.16 & 0.23 & 1.84 & 2.73 & 0.15 & 0.23 & 1.85 & 2.73 \\
\hline $\begin{array}{l}\text { Doxorubicin } \\
\text { liposomal }\end{array}$ & & 4.00 & 5.93 & 0.21 & 0.31 & 3.79 & 5.62 & 0.31 & 0.46 & 3.69 & 5.47 & 0.31 & 0.46 & 3.69 & 5.47 \\
\hline Gemcitabine & & 14.00 & 20.74 & 2.14 & 3.16 & 11.86 & 17.58 & 2.07 & 3.06 & 11.93 & 17.68 & 2.03 & 3.01 & 11.97 & 17.73 \\
\hline Paclitaxel & & 7.00 & 10.37 & 0.36 & 0.53 & 6.64 & 9.83 & 0.54 & 0.80 & 6.46 & 9.57 & 0.54 & 0.80 & 6.46 & 9.57 \\
\hline $\begin{array}{l}\text { Paclitaxel, albumin } \\
\text { bound }\end{array}$ & & 12.00 & 17.78 & 0.62 & 0.92 & 11.38 & 16.86 & 0.93 & 1.38 & 11.07 & 16.40 & 0.92 & 1.37 & 11.08 & 16.41 \\
\hline Trastuzumab & & 3.00 & 4.44 & 0.15 & 0.23 & 2.85 & 4.21 & 0.23 & 0.34 & 2.77 & 4.10 & 0.23 & 0.34 & 2.77 & 4.10 \\
\hline Vinorelbine & & 13.00 & 19.26 & 1.98 & 2.94 & 11.02 & 16.32 & 1.92 & 2.84 & 11.08 & 16.42 & 1.89 & 2.79 & 11.11 & 16.46 \\
\hline Othere & & 6.00 & 8.89 & 0.51 & 0.76 & 5.49 & 8.13 & 0.21 & 0.31 & 5.79 & 8.58 & 0.21 & 0.31 & 5.79 & 8.58 \\
\hline Ixabepilone & & $\mathrm{n} / \mathrm{a}$ & 0 & $\mathrm{n} / \mathrm{a}$ & 0 & 8.39 & 12.42 & $\mathrm{n} / \mathrm{a}$ & 0 & 8.64 & 12.79 & $\mathrm{n} / \mathrm{a}$ & 0 & 8.61 & 12.76 \\
\hline Totals & 148 & 100.00 & 148.13 & 8.39 & 12.42 & 100.00 & 148.13 & 8.64 & 12.79 & 100.00 & 148.13 & 8.61 & 12.76 & 100.00 & 148.31 \\
\hline $\begin{array}{l}{ }^{a} \text { Numbers shown in } \\
{ }^{b} \text { Market share analy } \\
{ }^{c} \text { Market share analy } \\
{ }^{d} \text { Market share analy } \\
\text { for forecasting. } \\
{ }^{e} \text { Other = tamoxifen, } \\
\text { ATC-p = pretreated }\end{array}$ & $\begin{array}{l}\text { tabl } \\
\text { s perf } \\
\text { s perf }\end{array}$ & $\begin{array}{l}\text { may not ex } \\
\text { rmed by Int } \\
\text { rmed by stu } \\
\text { rmed by stu } \\
\text { ole, gosereli }\end{array}$ & $\begin{array}{l}\text { xactly mu } \\
\text { atrinsiQ LI } \\
\text { udy author } \\
\text { udy autho } \\
\text { in. }\end{array}$ & $\begin{array}{l}\text { tiply or su } \\
\text { C (Waltho } \\
\text { s using pr } \\
\text { s using pr }\end{array}$ & $\begin{array}{l}\text { um to total } \\
\text { lam, MA) } \\
\text { roprietary } \\
\text { roprietary }\end{array}$ & $\begin{array}{l}\text { ls shown be } \\
\text { using propr } \\
\text { nonpublish } \\
\text { nonpublish }\end{array}$ & $\begin{array}{l}\text { ecause of } r \\
\text { rietary nor } \\
\text { hed data fr } \\
\text { hed data fr }\end{array}$ & $\begin{array}{l}\text { unding. } \\
\text { published } \\
\text { m Intrin } \\
\text { m Intrin }\end{array}$ & $\begin{array}{l}\text { d data for } \\
\text { siQ LLC } \\
\text { siQ LLC }\end{array}$ & $\begin{array}{l}2007 . \\
\text { Waltham, } 1 \\
\text { Waltham, } \\
\text { t cancer. }\end{array}$ & $\begin{array}{l}\text { MA) for } \\
\text { MA) for }\end{array}$ & $\begin{array}{l}8 . \\
\text { uary }\end{array}$ & 8 to Jo & $\operatorname{ary} 20$ & Is a basis \\
\hline
\end{tabular}

both AT-p and ATC-p patients. The reason for the low PMPM is primarily attributable to the size of the population estimated to receive ixabepilone therapy.

In another analysis of the budget impact of adding erlotinib to a regimen of gemcitabine as first-line treatment of locally advanced, nonresectable, or metastatic pancreatic cancer in the United States, for a hypothetical managed care plan of 500,000 members, with 43 patients newly diagnosed with pancreatic cancer each year, of whom 10 would be treated with gemcitabine+erlotinib, it was found that the new regimen would have a budget impact of $\$ 0.02$ PMPM..$^{37}$ Similar to the present study, the authors attributed the relatively low budgetary impact to the small patient population eligible to receive treatment.

Budget impact analyses have become an essential part of a comprehensive economic assessment of health care technology and are increasingly required, along with cost-effectiveness analyses, in decision making. ${ }^{16}$ Budget impact models are a valuable tool to health plans for making formulary or reimbursement decisions. Such models allow managed care organizations to gauge the potential economic impact resulting from the introduction of a new pharmacological treatment on medical and pharmacy budgets. ${ }^{38}$ In this model, using our current assumptions, the results suggest that the incremental cost impact to a pharmacy budget on a PMPM basis of adding ixabepilone is relatively small if the drug is used only in accordance with its current FDA-approved indications.

\section{Limitations}

As with all modeling exercises, our study has its limitations and has employed a number of assumptions. First, our model considers ixabepilone to be used only according to the FDAapproved label indications for MBC. Additional off-label uses, such as for cancers other than treatment-resistant MBC, were not considered in the model analysis.

Second, the model does not consider any nonformulary costs. As ixabepilone is a branded drug, it is more costly than generic 
TABLE 4 Total Annual Pharmacy Costs in Pre- and Post-Ixabepilone Market Scenarios, Incremental Budget Impact, and PMPM Costs for AT-p Population for Years 1 Through $3^{a}$

\begin{tabular}{|c|c|c|c|c|c|c|c|c|c|c|c|c|c|c|c|}
\hline & \multirow[b]{2}{*}{$\begin{array}{c}\text { Annual } \\
\text { Pharmacy } \\
\text { Cost }(\$)^{b}\end{array}$} & \multicolumn{2}{|c|}{ Pre-IXA } & \multicolumn{2}{|c|}{ Post- IXA Year 1} & \multicolumn{2}{|c|}{ Post- IXA Year 2} & \multicolumn{2}{|c|}{ Post- IXA Year 3} & \multicolumn{6}{|c|}{ Incremental Budget Impact } \\
\hline & & \# Pts & $\begin{array}{c}\text { Total } \\
\text { Annual } \\
\text { Cost (\$) }\end{array}$ & \# Pts & $\begin{array}{c}\text { Total } \\
\text { Annual } \\
\text { Cost }(\$)\end{array}$ & \# Pts & $\begin{array}{c}\text { Total } \\
\text { Annual } \\
\text { Cost }(\$)\end{array}$ & \# Pts & $\begin{array}{c}\text { Total } \\
\text { Annual } \\
\text { Cost }(\$)\end{array}$ & $\begin{array}{c}\text { Year } 1 \\
\text { Total } \\
\end{array}$ & $\begin{array}{l}\text { Year } 1 \\
\text { PMPM }\end{array}$ & $\begin{array}{c}\text { Year } 2 \\
\text { Total } \\
\end{array}$ & $\begin{array}{l}\text { Year } 2 \\
\text { PMPM }\end{array}$ & $\begin{array}{c}\text { Year } 3 \\
\text { Total } \\
\end{array}$ & $\begin{array}{l}\text { Year } 3 \\
\text { PMPM } \\
\end{array}$ \\
\hline $\begin{array}{l}\text { Column } \\
\text { Number (C) }\end{array}$ & 1 & 2 & 3 & 4 & 5 & 6 & 7 & 8 & 9 & 10 & 11 & 12 & 13 & 14 & 15 \\
\hline Calculation & & & $\mathrm{ClxC2}$ & & $\mathrm{ClxC4}$ & & ClxC6 & & $\mathrm{ClxC8}$ & C5-C3 & $\begin{array}{c}\mathrm{C} 10 /(1 \\
\left.\times 10^{6}\right) / 12 \\
\end{array}$ & $\mathrm{C} 7-\mathrm{C} 3$ & $\begin{array}{c}\mathrm{C} 12 /(1 \\
\left.\mathrm{x} 10^{6}\right) / 12 \\
\end{array}$ & C9-C3 & $\begin{array}{c}\mathrm{Cl} 4 /(1 \\
\left.\mathrm{x} 10^{6}\right) / 12 \\
\end{array}$ \\
\hline Bevacizumab & 19,443 & 0.97 & 18,830 & 0.96 & 18,642 & 0.96 & 18,642 & 0.96 & 18,642 & -188 & $\mathrm{n} / \mathrm{a}$ & -188 & $\mathrm{n} / \mathrm{a}$ & -188 & $\mathrm{n} / \mathrm{a}$ \\
\hline Capecitabine & 13,485 & 12.59 & 169,782 & 12.24 & 165,029 & 12.24 & 165,114 & 12.25 & 165,199 & $-4,754$ & $\mathrm{n} / \mathrm{a}$ & $-4,669$ & $\mathrm{n} / \mathrm{a}$ & $-4,584$ & $\mathrm{n} / \mathrm{a}$ \\
\hline Carboplatin & 8,357 & 6.78 & 56,656 & 6.71 & 56,033 & 6.71 & 56,090 & 6.71 & 56,090 & -623 & $\mathrm{n} / \mathrm{a}$ & -567 & $\mathrm{n} / \mathrm{a}$ & -567 & $\mathrm{n} / \mathrm{a}$ \\
\hline Cyclophosphamide & 5,092 & 3.87 & 19,727 & 3.83 & 19,510 & 3.84 & 19,530 & 3.84 & 19,530 & -217 & $\mathrm{n} / \mathrm{a}$ & -197 & $\mathrm{n} / \mathrm{a}$ & -197 & $\mathrm{n} / \mathrm{a}$ \\
\hline Docetaxel & 19,053 & 9.69 & 184,534 & 9.58 & 182,504 & 9.59 & 182,689 & 9.59 & 182,689 & $-2,030$ & $\mathrm{n} / \mathrm{a}$ & $-1,845$ & $\mathrm{n} / \mathrm{a}$ & $-1,845$ & $\mathrm{n} / \mathrm{a}$ \\
\hline Doxorubicin & 396 & 2.91 & 1,150 & 2.87 & 1,138 & 2.88 & 1,139 & 2.88 & 1,139 & -13 & $\mathrm{n} / \mathrm{a}$ & -12 & $\mathrm{n} / \mathrm{a}$ & -12 & $\mathrm{n} / \mathrm{a}$ \\
\hline Fluorouracil & 54 & 1.94 & 105 & 1.92 & 104 & 1.92 & 104 & 1.92 & 104 & -1 & $\mathrm{n} / \mathrm{a}$ & -1 & $\mathrm{n} / \mathrm{a}$ & -1 & $\mathrm{n} / \mathrm{a}$ \\
\hline Gemcitabine & 17,586 & 12.59 & 221,420 & 11.95 & 210,239 & 11.94 & 210,017 & 11.96 & 210,350 & $-11,182$ & $\mathrm{n} / \mathrm{a}$ & $-11,403$ & $\mathrm{n} / \mathrm{a}$ & $-11,071$ & $\mathrm{n} / \mathrm{a}$ \\
\hline Irinotecan & 5,425 & 1.94 & 10,507 & 1.92 & 10,392 & 1.92 & 10,403 & 1.92 & 10,403 & -116 & $\mathrm{n} / \mathrm{a}$ & -105 & $\mathrm{n} / \mathrm{a}$ & -105 & $\mathrm{n} / \mathrm{a}$ \\
\hline Methotrexate & 168 & 1.94 & 326 & 1.92 & 323 & 1.92 & 323 & 1.92 & 323 & -4 & $\mathrm{n} / \mathrm{a}$ & -3 & $\mathrm{n} / \mathrm{a}$ & -3 & $\mathrm{n} / \mathrm{a}$ \\
\hline Paclitaxel & 5,795 & 9.69 & 56,128 & 9.58 & 55,511 & 9.59 & 55,567 & 9.59 & 55,567 & -617 & $\mathrm{n} / \mathrm{a}$ & -561 & $\mathrm{n} / \mathrm{a}$ & -561 & $\mathrm{n} / \mathrm{a}$ \\
\hline $\begin{array}{l}\text { Paclitaxel, albumin } \\
\text { bound }\end{array}$ & 23,956 & 9.69 & 232,020 & 9.58 & 229,468 & 9.59 & 229,700 & 9.59 & 229,700 & $-2,552$ & $\mathrm{n} / \mathrm{a}$ & $-2,320$ & $\mathrm{n} / \mathrm{a}$ & $-2,320$ & $\mathrm{n} / \mathrm{a}$ \\
\hline Trastuzumab & 31,370 & 1.94 & 60,765 & 1.92 & 60,097 & 1.92 & 60,158 & 1.92 & 60,158 & -668 & $\mathrm{n} / \mathrm{a}$ & -608 & $\mathrm{n} / \mathrm{a}$ & -608 & $\mathrm{n} / \mathrm{a}$ \\
\hline Vinorelbine & 22,512 & 14.53 & 327,047 & 14.12 & 317,890 & 14.13 & 318,054 & 14.14 & 318,217 & $-9,157$ & $\mathrm{n} / \mathrm{a}$ & $-8,994$ & $\mathrm{n} / \mathrm{a}$ & $-8,830$ & $\mathrm{n} / \mathrm{a}$ \\
\hline Otherc & 22,512 & 5.81 & 130,819 & 5.75 & 129,445 & 5.75 & 129,445 & 5.75 & 129,511 & $-1,374$ & $\mathrm{n} / \mathrm{a}$ & $-1,374$ & $\mathrm{n} / \mathrm{a}$ & $-1,308$ & $\mathrm{n} / \mathrm{a}$ \\
\hline $\begin{array}{l}\text { Ixabepilone + } \\
\text { capecitabine }\end{array}$ & 28,008 & $\mathrm{n} / \mathrm{a}$ & 0 & 2.02 & 56,599 & 1.97 & 55,134 & 1.93 & 54,144 & 56,599 & $\mathrm{n} / \mathrm{a}$ & 55,134 & $\mathrm{n} / \mathrm{a}$ & 54,144 & $\mathrm{n} / \mathrm{a}$ \\
\hline Totals & 223,213 & 96.85 & $1,489,821$ & 96.85 & $1,512,925$ & 96.85 & $1,512,109$ & 96.85 & $1,511,764$ & 23,103 & 0.002 & 22,287 & 0.002 & 21,943 & 0.002 \\
\hline \multicolumn{16}{|c|}{$\begin{array}{l}\text { aNumbers shown in the table may not exactly multiply or sum to totals shown because of rounding. } \\
\text { bCalculated using WAC list price (FirstDataBank Inc., San Bruno, CA), } 20 \text { accessed on March 2009, manufacturers' product information sheets for dosing, } 21-35 \text { and } \\
\text { assumptions about the median cycle lengths for all drug therapies that were based on the opinions of physicians employed or retained by the study sponsor. } \\
\text { cOther = tamoxifen, anastrozole, goserelin. } \\
\text { AT-p = pretreated with anthracyclines and taxanes; IXA =ixabepilone; PMPM = per member per month; Pts = patients; WAC= wholesale acquisition cost. }\end{array}$} \\
\hline
\end{tabular}

MBC treatment options and thus would be associated with higher administration charges compared with less expensive treatment options. However, the MBC patient population estimated to be eligible to receive ixabepilone therapy is relatively small, thus making any additional costs imposed upon the overall budget to be minor. This assumption was tested in our sensitivity analysis by varying the price of ixabeplione $+/-50 \%$, which did not appear to have a significant impact on the results.

A third potential limitation may be inherent in the market data that were used for the analysis. The AT-p and ATC-p prevalence rates were taken from 2007 market research data for 36 states that were purchased from a proprietary source. The real-world drug utilization data from January 2007 to January 2009 used as the basis for the pre- and post-ixabepilone market share data were also purchased from the same proprietary source. Although we believe that these market data are the best available, there is the potential for over- or underestimation of prevalence rates or mar- ket shares for any given drug attributable to the way the data are collected and aggregated. However, it is expected that these limitations should apply to all of the market shares values attained. We tested this uncertainty by varying the projected ixabepilone market uptake in $a+/-50 \%$ range, which did not appear to have a significant impact on the results.

\section{Conclusion}

Given the estimated number of patients eligible for ixabepilone monotherapy in a hypothetical 1 million-member population (15 MBC patients, comprised of both AT-p and ATC-p patients), this budget impact model predicted a relatively minimal incremental budget impact following the introduction of coverage for ixabepilone in accordance with its labeled indications. The estimated incremental increase shared across all plan members in 2009 dollars was at most \$0.006 PMPM for each year during the analyzed 3-year period. 
TABLE 5 Total Annual Pharmacy Costs in Pre- and Post-Ixabepilone Market Scenarios, Incremental Budget Impact, and PMPM Costs for ATC-p Population for Years 1 Through $3^{a}$

\begin{tabular}{|c|c|c|c|c|c|c|c|c|c|c|c|c|c|c|c|}
\hline & \multirow[b]{2}{*}{$\begin{array}{c}\text { Annual } \\
\text { Pharmacy } \\
\text { Cost }(\$)^{b}\end{array}$} & \multicolumn{2}{|c|}{ Pre-IXA } & \multicolumn{2}{|c|}{ Post- IXA Year 1} & \multicolumn{2}{|c|}{ Post- IXA Year 2} & \multicolumn{2}{|c|}{ Post- IXA Year 3} & \multicolumn{6}{|c|}{ Incremental Budget Impact } \\
\hline & & \# Pts & $\begin{array}{c}\text { Total } \\
\text { Annual } \\
\text { Cost }(\$)\end{array}$ & \# Pts & $\begin{array}{c}\text { Total } \\
\text { Annual } \\
\text { Cost }(\$)\end{array}$ & \# Pts & $\begin{array}{c}\text { Total } \\
\text { Annual } \\
\text { Cost }(\$)\end{array}$ & \# Pts & $\begin{array}{c}\text { Total } \\
\text { Annual } \\
\text { Cost }(\$)\end{array}$ & $\begin{array}{c}\text { Year } 1 \\
\text { Total }\end{array}$ & $\begin{array}{l}\text { Year } 1 \\
\text { PMPM }\end{array}$ & $\begin{array}{c}\text { Year } 2 \\
\text { Total }\end{array}$ & $\begin{array}{l}\text { Year } 2 \\
\text { PMPM }\end{array}$ & $\begin{array}{c}\text { Year } 3 \\
\text { Total }\end{array}$ & $\begin{array}{l}\text { Year } 3 \\
\text { PMPM }\end{array}$ \\
\hline $\begin{array}{l}\text { Column Number } \\
\text { (C) }\end{array}$ & 1 & 2 & 3 & 4 & 5 & 6 & 7 & 8 & 9 & 10 & 11 & 12 & 13 & 14 & 15 \\
\hline Calculation & & & $\mathrm{ClxC2}$ & & $\mathrm{ClxC4}$ & & $\mathrm{ClxC6}$ & & $\mathrm{ClxC} 8$ & $\mathrm{C} 5-\mathrm{C} 3$ & \begin{tabular}{|l|}
$\mathrm{C} 10 /(1 \mathrm{x}$ \\
$\left.10^{6}\right) / 12$ \\
\end{tabular} & $\mathrm{C} 7-\mathrm{C} 3$ & \begin{tabular}{|l|}
$\mathrm{C} 12 /(1 \mathrm{x}$ \\
$\left.10^{6}\right) / 12$
\end{tabular} & $\mathrm{C} 9-\mathrm{C} 3$ & $\begin{array}{l}\text { C14/(1x } \\
\left.10^{6}\right) / 12\end{array}$ \\
\hline Capecitabine & $13,484.80$ & 29.63 & 399,489 & 27.64 & 372,723 & 28.44 & 383,509 & 28.34 & 382,111 & $-26,766$ & $\mathrm{n} / \mathrm{a}$ & $-15,980$ & $\mathrm{n} / \mathrm{a}$ & $-17,378$ & $\mathrm{n} / \mathrm{a}$ \\
\hline Carboplatin & $8,356.86$ & 7.41 & 61,893 & 7.02 & 58,706 & 6.83 & 57,097 & 6.84 & 57,127 & $-3,188$ & $\mathrm{n} / \mathrm{a}$ & $-4,797$ & $\mathrm{n} / \mathrm{a}$ & $-4,766$ & $\mathrm{n} / \mathrm{a}$ \\
\hline Cyclophosphamide & $5,092.00$ & 4.44 & 22,628 & 4.21 & 21,462 & 4.10 & 20,874 & 4.10 & 20,885 & $-1,165$ & $\mathrm{n} / \mathrm{a}$ & $-1,754$ & $\mathrm{n} / \mathrm{a}$ & $-1,742$ & $\mathrm{n} / \mathrm{a}$ \\
\hline Docetaxel & $19,053.32$ & 16.29 & 310,451 & 15.45 & 294,463 & 15.03 & 286,391 & 15.04 & 286,547 & \begin{tabular}{|l|}
$-15,988$ \\
\end{tabular} & $\mathrm{n} / \mathrm{a}$ & $-24,060$ & $\mathrm{n} / \mathrm{a}$ & $-23,905$ & $n / a$ \\
\hline Doxorubicin & 396.00 & 2.96 & 1,173 & 2.81 & 1,113 & 2.73 & 1,082 & 2.73 & 1,083 & -60 & $\mathrm{n} / \mathrm{a}$ & -91 & $\mathrm{n} / \mathrm{a}$ & -90 & $\mathrm{n} / \mathrm{a}$ \\
\hline $\begin{array}{l}\text { Doxorubicin } \\
\text { liposomal }\end{array}$ & 396.00 & 5.93 & 2,346 & 5.62 & 2,225 & 5.47 & 2,164 & 5.47 & 2,166 & -121 & $\mathrm{n} / \mathrm{a}$ & \begin{tabular}{|c|}
-182 \\
\end{tabular} & $\mathrm{n} / \mathrm{a}$ & -181 & $\mathrm{n} / \mathrm{a}$ \\
\hline Gemcitabine & $17,586.08$ & 20.74 & 364,693 & 17.58 & 309,077 & 17.68 & 310,901 & 17.73 & 311,812 & $-55,616$ & $\mathrm{n} / \mathrm{a}$ & $-53,792$ & $\mathrm{n} / \mathrm{a}$ & $-52,880$ & $\mathrm{n} / \mathrm{a}$ \\
\hline Paclitaxel & $5,795.30$ & 10.37 & 60,090 & 9.83 & 56,996 & 9.57 & 55,433 & 9.57 & 55,463 & $-3,095$ & $\mathrm{n} / \mathrm{a}$ & $-4,657$ & $\mathrm{n} / \mathrm{a}$ & $-4,627$ & $\mathrm{n} / \mathrm{a}$ \\
\hline $\begin{array}{l}\text { Paclitaxel, albumin } \\
\text { bound }\end{array}$ & $23,956.31$ & 17.78 & 425,825 & 16.86 & 403,895 & 16.40 & 392,824 & 16.41 & 393,037 & \begin{tabular}{|l|}
$-21,930$ \\
\end{tabular} & $\mathrm{n} / \mathrm{a}$ & $-33,001$ & $\mathrm{n} / \mathrm{a}$ & $-32,789$ & $\mathrm{n} / \mathrm{a}$ \\
\hline Trastuzumab & $31,370.32$ & 4.44 & 139,402 & 4.21 & 132,223 & 4.10 & 128,599 & 4.10 & 128,668 & $-7,179$ & $\mathrm{n} / \mathrm{a}$ & $-10,804$ & $\mathrm{n} / \mathrm{a}$ & $-10,734$ & $\mathrm{n} / \mathrm{a}$ \\
\hline Vinorelbine & $22,512.00$ & 19.26 & 433,499 & 16.32 & 367,390 & 16.42 & 369,558 & 16.64 & 370,641 & \begin{tabular}{|l|}
$-66,109$ \\
\end{tabular} & $\mathrm{n} / \mathrm{a}$ & $-63,941$ & $\mathrm{n} / \mathrm{a}$ & $-62,857$ & $\mathrm{n} / \mathrm{a}$ \\
\hline Otherc & 22,512 & 9 & 200,076 & 8 & 183,070 & 9 & 193,074 & 9 & 193,074 & $-17,006$ & $\mathrm{n} / \mathrm{a}$ & $-7,003$ & $\mathrm{n} / \mathrm{a}$ & $-7,003$ & $\mathrm{n} / \mathrm{a}$ \\
\hline Ixabepilone & 20,898 & 0 & 0.00 & 12 & 259,650 & 13 & 267,296 & 13 & 266,646 & \begin{tabular}{|l|}
259,650 \\
\end{tabular} & $\mathrm{n} / \mathrm{a}$ & 267,296 & $\mathrm{n} / \mathrm{a}$ & $-266,646$ & $\mathrm{n} / \mathrm{a}$ \\
\hline Totals & 191,409 & 148 & $2,421,566$ & 148 & $2,462,994$ & 148 & $2,468,802$ & 148 & $2,469,261$ & 41,428 & 0.003 & 47,236 & 0.004 & 47,695 & 0.004 \\
\hline
\end{tabular}

a Numbers shown in the table may not exactly multiply or sum to totals shown because of rounding.

${ }^{b}$ Calculated using WAC list price (FirstDataBank Inc., San Bruno, CA), 20 accessed on March 2009, manufacturers' product information sheets for dosing, 21-35 and assumptions about median cycle lengths for all drug therapies that were based on the opinions of physicians employed or retained by the study sponsor.

cOther = tamoxifen, anastrozole, goserelin.

ATC- $p=$ pretreated with anthracyclines, taxanes, and capecitabine; IXA =ixabepilone; $P M P M=$ per member per month; Pts = patients; WAC=wholesale acquisition cost

\section{Authors}

JOANNE HO, PhD, is Senior Research Associate, Dymaxium Inc., Toronto, Ontario, Canada. LIHUA ZHANG, MD, PhD, is Associate Director of Global Outcomes Research, Bristol-Myers Squibb Company, Plansboro, New Jersey. LORA TODOROVA, MPH, is presently Manager of Global Health Economics and Outcomes Research, Novartis Pharmaceuticals, Basel, Switzerland; at the time of the work on this project she was an employee of Dymaxium Inc., Toronto, Ontario, Canada. FINLAY WHILLANS is presently Manager of Health Outcomes Research and Pricing, Wyeth Pharmaceuticals, Toronto, Ontario, Canada; at the time of the work on this project he was an employee of Dymaxium, Toronto, Ontario, Canada. PATRICIA COREY-LISLE, PhD, RN, is Group Director of Global Outcomes Research, Bristol-Myers Squibb Company, Wallingford, Connecticut. YONG YUAN, PhD, is Director of Global Outcomes Research, Bristol-Myers Squibb Company, Plansboro, New Jersey.

AUTHOR CORRESPONDENCE: Yong Yuan, PhD, Bristol-Myers Squibb Company, P.O. Box 4500, Princeton, NJ 08543-4000. Tel. 609.897.2688; Fax: 609.897.6319; E-mail: yong.yuan@bms.com

\section{DISCLOSURES}

This study was funded by Bristol-Myers Squibb Company (BMS), and 3 of the authors (Zhang, Corey-Lisle, and Yuan) are employed by BMS Company. Dymaxium Inc. acted as a paid consultant for BMS; Dymaxium built the budget impact model, forecasted market shares for years 2 and 3, and performed the model analyses. Tasks were completed with guidance by BMS. Market data were purchased by BMS from IntrinsiQ and provided to Dymaxium. An abstract based on this study was presented at the International Society of Pharmacoeconomics and Outcomes Research 13th annual meeting in Toronto, Ontario, Canada, May 2008.

Yuan was responsible for study concept and design with the assistance of all other authors. Zhang, Ho, and Whillans performed the data collection. Ho performed data interpretation and wrote the manuscript, with the assistance of the other authors. Revisions were made primarily by Ho.

\section{REFERENCES}

1. American Cancer Society. Cancer Facts and Figures 2009. Available at: http://www.cancer.org/downloads/STT/500809web.pdf. Accessed July 10, 2009.

2. Greenberg PA, Hortobagyi GN, Smith TL, Ziegler LD, Frye DK, Buzdar AU. Long-term follow-up of patients with complete remission following combination chemotherapy for metastatic breast cancer. J Clin Oncol. 1996;14(8):2197-205. 
3. Cardoso F, Di LA, Lohrisch C, Bernard C, Ferreira F, Piccart MJ. Second and subsequent lines of chemotherapy for metastatic breast cancer: what did we learn in the last two decades? Ann Oncol. 2002;13(2):197-207.

4. Chia SK, Speers CH, D'yachkova Y, et al. The impact of new chemotherapeutic and hormone agents on survival in a population-based cohort of women with metastatic breast cancer. Cancer. 2007;110(5):973-79.

5. Takeda AL, Jones J, Loveman E, Tan SC, Clegg AJ. The clinical effectiveness and cost-effectiveness of gemcitabine for metastatic breast cancer: a systematic review and economic evaluation. Health Technol Assess. 2007;11(19):iii,ix-xi,1-62.

6. Hortobagyi GN. Treatment of breast cancer. N Engl J Med. 1998;339(14): 974-84.

7. O'Shaughnessy J, Twelves C, Aapro M. Treatment for anthracycline-pretreated metastatic breast cancer. Oncologist. 2002;7(Suppl 6):4-12.

8. Vahdat LT, Thomas E., Li R., et al. Phase III trial of ixabepilone plus capecitabine compared to capecitabine alone in patients with metastatic breast cancer (MBC) previously treated or resistant to an anthracycline and resistant to taxanes. Poster presented at: 2007 American Society of Clinical Oncology Annual Meeting; June 1-5, 2007; Chicago, IL.

9. Geyer CE, Forster J, Lindquist D, et al. Lapatinib plus capecitabine for HER2-positive advanced breast cancer. N Engl J Med. 2006;355(26):2733-43. Available at: http://content.nejm.org/cgi/reprint/355/26/2733.pdf. Accessed July 9, 2009.

10. Miller KD, Chap LI, Holmes FA, et al. Randomized phase III trial of capecitabine compared with bevacizumab plus capecitabine in patients with previously treated metastatic breast cancer. J Clin Oncol. 2005;23(4):792-99.

11. Holfe G RH. Epothilone, a myxobacterial metabolite with promising antitumor activity. In: Cragg GM, Kingston DGI, Newman DJ, eds. Anticancer Agents From Natural Products. Boca Raton, London: Taylor and Francis Group; 2005:413-50.

12. Lee FY, Borzilleri R, Fairchild CR, et al. BMS-247550: a novel epothilone analog with a mode of action similar to paclitaxel but possessing superior antitumor efficacy. Clin Cancer Res. 2001;7(5):1429-37.

13. Perez EA, Lerzo G, Pivot X, et al. Efficacy and safety of ixabepilone (BMS-247550) in a phase II study of patients with advanced breast cancer resistant to an anthracycline, a taxane, and capecitabine. J Clin Oncol. 2007;25(23):3407-14.

14. Vahdat L. Ixabepilone: a novel antineoplastic agent with low susceptibility to multiple tumor resistance mechanisms. Oncologist. 2008;13(3):214-21.

15. Thomas ES, Gomez HL, Li RK, et al. Ixabepilone plus capecitabine for metastatic breast cancer progressing after anthracycline and taxane treatment. J Clin Oncol. 2007;25(33):5210-17. Available at: http://jco.ascopubs. org/cgi/reprint/25/33/5210. Accessed July 15, 2009.

16. Mauskopf JA, Sullivan SD, Annemans L, et al. Principles of good practice for budget impact analysis: report of the ISPOR Task Force on good research practices_budget impact analysis. Value Health. 2007;10(5):336-47.

17. Surveillance, Epidemiology, and End Results (SEER) Program Table 1-22 U.S. Complete Prevalence Counts, Invasive Cancers Only, January 1, 2005 By Age At Prevalence. Cancer Statistics Branch. Available at: http://seer.cancer.gov/csr/1975_2005/results_single/sect_01_table.22_2pgs.pdf. Accessed July 9, 2009.

18. CancerMpact. Comprehensive Cancer Epidemiology Database: 2008. Proprietary and nonpublished data; available for purchase at: http://www. mattsonjack.com/patient_metrics.asp. Accessed July 9, 2009.

19. IntrinsiQ. Research Market Share Data: 2007. Proprietary and nonpublished data, available for purchase at: http://www.intrinsiq.com/index.aspx. Accessed July 9, 2009.

20. Wholesale Acquisition Cost (March 2009). First DataBank Inc. Available for purchase at: www.firstdatabank.com/products/price_point_rx/. Initially accessed March 2009. Last accessed July 9, 2009.
21. U.S. Food and Drug Administration. Approved label for Avastin (bevacizumab). Available at: http://www.accessdata.fda.gov/drugsatfda_docs/ label/2009/125085s0169lbl.pdf. Accessed July 6, 2009.

22. Rheumatrex (methotrexate) Product Information. Stada Pharmaceuticals Inc. Available at: http://www.rheumatrex.info/pdf/RheumatrexPackageInsert pdf. Accessed July 6, 2009.

23. U.S. Food and Drug Administration. Approved label for Camptosar irinotecan. Available at: http://www.accessdata.fda.gov/drugsatfda_docs/ label/2006/020571s030lbl.pdf. Accessed July 6, 2009.

24. U.S. Food and Drug Administration. Approved label for Herceptin (trastuzumab). Available at: http://www.accessdata.fda.gov/drugsatfda_docs/ label/2008/103792s5175lbl.pdf. Accessed July 6, 2009

25. U.S. Food and Drug Administration. Approved label for Abraxane for Injectable Suspension (paclitaxel protein-bound particles for injectable suspension) (albumin-bound). Available at: http://www.accessdata.fda.gov/ drugsatfda_docs/label/2008/021660s013lbl.pdf. Accessed July 6, 2009.

26. U.S. Food and Drug Administration. Approved label for Gemzar (gemcitabine $\mathrm{HCl})$. Available at: http://www.accessdata.fda.gov/drugsatfda_docs/ label/2005/020509s033lbl.pdf. Accessed July 6, 2009.

27. U.S. Food and Drug Administration. Approved label for Taxotere (docetaxel). Available at: http://www.accessdata.fda.gov/drugsatfda_docs/ label/2007/020449s045lbl.pdf. Accessed July 6, 2009.

28. U.S. Food and Drug Administration. Approved label for Xeloda (capecitabine). Available at: http://www.accessdata.fda.gov/drugsatfda_docs/ label/2005/020896s016lbl.pdf. Accessed July 6, 2009.

29. Fluorouracil (Fluorouracil Injection, USP) Product Information. Parenta pharmaceuticals. Available at: http://www.parentarx.com/files/prodfiles/ Approved_5FU_PI06.30.09.pdf. Accessed July 6, 2009.

30. U.S. Food and Drug Administration. Approved label for Doxorubicin Hydrochloride. Available at: http://www.accessdata.fda.gov/drugsatfda_docs/ label/2003/050467s068lbl.pdf. Accessed July 6, 2009.

31. Cytoxan (cyclophosphamide for injection, USP) Product Information. Bristol-Myers Squibb Company. Available at: http://packageinserts.bms.com/ pi/pi_cytoxan.pdf. Accessed July 6, 2009.

32. U.S. Food and Drug Administration. Approved label for Paraplatin (carboplatin aqueous solution) Injection. Available at: http://www.accessdata.fda.gov/drugsatfda_docs/label/2004/20452scs001_paraplatin_lbl.pdf. Accessed July 6, 2009.

33. U.S. Food and Drug Administration. Approved label for Taxol (paclitaxel) Injection. Available at: http://www.accessdata.fda.gov/drugsatfda_ docs/label/2000/20262S36LBL.PDF. Accessed July 6, 2009.

34. U.S. Food and Drug Administration. Approved label for Ixempra Kit (ixabepilone) for Injection, Available at: http://www.accessdata.fda.gov/drugsatfda_docs/label/2009/022065s001lbl.pdf. Accessed July 6, 2009.

35. U.S. Food and Drug Administration. Approved label for Vinorelbine Injection USP. Available at: http://www.bedfordlabs.com/BedfordLabsWeb/ products/inserts/VRLB-P01.pdf. Accessed July 11, 2009.

36. Curtiss FR. Pharmacy benefit spending on oral chemotherapy drugs. $J$ Manag Care Pharm. 2006;12(7):570-77. Available at: http://amcp.org/data/ jmcp/contemporary_subjects_570_577.pdf.

37. Danese MD, Reyes C, Northridge K, Lubeck D, Lin CY, O'Connor P. Budget impact model of adding erlotinib to a regimen of gemcitabine for the treatment of locally advanced, nonresectable or metastatic pancreatic cancer. Clin Ther. 2008;30(4):775-84.

38. Chang J, Sung J. Health plan budget impact analysis for pimecrolimus. J Manag Care Pharm. 2005;11(1):66-73. Available at: http://www.amcp.org/ data/jmcp/Form_Manag_66-73.pdf. 